\title{
Bone Mineralization in Rhythmic Gymnasts before Puberty: No Longitudinal Associations with Adipocytokine and Ghrelin Levels
}

\author{
Anna-Liisa Parm ${ }^{a}$ Jaak Jürimäe ${ }^{a}$ Meeli Saar $^{a} \quad$ Kristel Pärna $^{a}$ Vallo Tillmann ${ }^{b}$ \\ Katre Maasalu $^{c}$ Inga Neissaar ${ }^{a}$ Toivo Jürimäe ${ }^{a}$ \\ ${ }^{a}$ Faculty of Exercise and Sport Sciences, ${ }^{b}$ Department of Pediatrics, and ${ }^{\mathrm{C} C l i n i c s}$ of Traumatology \\ and Orthopedics, Faculty of Medicine, University of Tartu, Tartu, Estonia
}

\section{Key Words}

Rhythmic gymnasts • Bone mineral density •

Adipocytokines $\cdot$ Ghrelin

\begin{abstract}
Aim: Relationships between change of bone mineral density (BMD) and baseline adipocytokine and ghrelin levels over 12 months in prepubertal rhythmic gymnasts (RG) and agematched untrained controls (UC) were studied. Methods: Adipocytokine, ghrelin, body composition, BMD and bone age values were measured in $\mathrm{RG}(8.0 \pm 0.6$ years; $n=33)$ and UC $(8.2 \pm 0.6$ years; $n=35)$. Results: Increases in BMD and body composition parameters were seen in both groups as a result of the 12-month study period. Adiponectin increased and ghrelin decreased in both groups, leptin increased only in UC. Measured bone age, body composition and hormone values did not predict increases in BMD values in $R G$. The variables that were associated with increases in whole-body $(\Delta \mathrm{WB})$ and femoral neck ( $\triangle \mathrm{FN}) \mathrm{BMD}$ values were fat mass and fat-free mass together in UC. Ghrelin and adiponectin were the most important hormonal predictors of $\triangle W B B M D$ and $\triangle F N B M D$ values in UC, respectively. In RG, adiponectin and ghrelin levels did not predict increases in measured BMD values. Conclusion: Body composition parameters and hor-
\end{abstract}

\section{KARGER}

Fax +4161306 1234

E-Mail karger@karger.ch

www.karger.com
(C) 2012 S. Karger AG, Basel

$1663-2818 / 12 / 0776-0369 \$ 38.00 / 0$

Accessible online at:

www.karger.com/hrp mone levels did not predict normal growth in measured BMD values as a result of the 12-month study period in RG. However, leptin together with specific body composition variables was associated with an increase in $\triangle W B B M D$ value in UC.

Copyright $\odot 2012$ S. Karger AG, Basel

\section{Introduction}

Prepubertal time period is a very sensitive period for bone mineral accumulation in children [1], which is influenced by genetic potential, endocrine status, nutritional factors, body composition and physical activity [2, 3]. Regular high-impact weight-bearing physical activity during growth and maturation plays an important role in maximizing bone mineral mass gain [3]. A number of cross-sectional studies have demonstrated significantly higher bone mineral density (BMD) values at the loadbearing sites of the skeleton in prepubertal [4], early pubertal [5] and adolescent [6] rhythmic gymnasts (RG) compared to untrained controls (UC). In addition, a recent cross-sectional study by Maimoun et al. [7] showed that BMD values are higher over the course of pubertal development in elite RG, where more mature girls dem- 
onstrated significantly higher BMD values compared with less mature girls. However, there are fewer longitudinal data on specific bone mineral accrual during the prepubertal growth in RG who start to exercise with relatively high training loads already at a relatively early age [4].

Body mass has been considered as one of the strongest predictors of BMD [8]. Recent reports indicate that fat (FM) and fat-free (FFM) masses are positively related to BMD in prepubertal girls [2, 4]. Furthermore, a positive effect of FM on bone mineralization has been attributed to a combination of mechanical load exerted on the skeleton by FM [8] and by the adipose-modulated biochemical signals of appetite regulation and energy homeostasis $[9,10]$. Among the numerous adipose-modulated biochemical signals that may participate in energy homeostasis and contribute to the relationship between FM and $\mathrm{BMD}$ in lean children and adolescents are leptin $[6,9]$, adiponectin $[11,12]$ and the gut hormone ghrelin $[4,10]$. In general, in the presence of elevated energy expenditure, chronic physical activity decreases leptin, and increases adiponectin and ghrelin concentrations in athletes [13]. Leptin concentrations have been related to FM and BMD values in healthy lean prepubertal girls $[2,9]$, while the impact of lowered leptin concentrations on bone mass acquisition in the presence of elevated energy expenditure and reduced FM remains questionable in prepubertal and pubertal female RG $[4,5,7,14,15]$. Adiponectin has been related to BMD values in healthy untrained adolescent girls $[11,12]$, while adiponectin did not predict BMD among prepubertal [4] and adolescent [16] female athletes. Similarly, circulating ghrelin has been reported to influence bone mineralization in untrained prepubertal [4] and adolescent [17] girls. In contrast, our recent studies have demonstrated that ghrelin concentrations were not related to BMD values in female prepubertal RG [4] and pubertal swimmers [18]. Accordingly, to date, the reports on the possible interactions between adipocytokines and ghrelin concentrations with bone mineralization during linear growth remain contradictory. Therefore, leptin concentrations increase progressively during growth and maturation in girls following a pattern that parallels increases in subcutaneous fat depot [19] and also in body mass [7,20]. In addition, it has been reported that circulating adiponectin increases [21] and ghrelin decreases [22] during linear growth in children.

Leptin, adiponectin and ghrelin seem to play an important role in the regulation of body composition during growth and maturation in children. Furthermore, regular physical activity may modify the possible relation- ships between these circulating adipocytokine and ghrelin levels with specific body composition parameters in children $[6,7]$. However, to our best knowledge, no studies have been conducted to longitudinally examine the possible role of different adipocytokines and ghrelin at the same time on the development of BMD in a specific group of physically active prepubertal girls. Therefore, a recent 12-month follow-up study found that baseline leptin was not associated with BMD gain in peripubertal RG (10.7-16.1 years old) [15]. Accordingly, we conducted a 12-month prospective study to investigate the relationship between baseline leptin, adiponectin and ghrelin concentrations with the normal increase in BMD values in a specific group of prepubertal RG and UC. In addition, we evaluated different body composition values that are known to affect bone metabolism.

\section{Subjects and Methods}

\section{Subjects}

The study protocol was reviewed and approved by the Medical Ethics Committee of the University of Tartu (Estonia). All RG, UC and their parents gave written informed consent before entering the study. Participants of this study were 68 7- to 9-year-old girls from different schools in Estonia. The participants were divided into RG $(n=33)$ and $U C(n=35)$. All RG were recruited from local training groups and had usually trained 10-12 h/week (5-6 training sessions per week) for the past 2 years before starting the study. However, there were some easy periods in their training when gymnasts trained a mean $6 \mathrm{~h} /$ week (3 training sessions per week). All these RG were training in the same club and had very similar training lessons (ballet, acrobatics and rhythmic gymnastics training). Most training sessions lasted $2 \mathrm{~h}$ and consisted of a warm-up, routine training, and strength and stretching exercises. All RG were competing at the national level. Controls had compulsory physical education classes twice a week at school. Participation only in school's physical education classes was inclusion criteria for UC subjects [4]. All participants were free from present or past diseases known to affect skeletal metabolism, and none of the girls were receiving medications known to affect bone. Throughout the study period, no restrictions were placed on dietary intake and participants consumed their usual everyday diet $[4,23]$.

\section{Methods}

Body height was measured using a Martin metal anthropometer to the nearest $0.1 \mathrm{~cm}$ according to the standard technique, body mass was measured with minimal clothing to the nearest $0.05 \mathrm{~kg}$ with a medical electronic scale (A\&D Instruments, Ltd, Abingdon, UK) and body mass index (BMI) was calculated as body mass divided by square of body height. Pubertal development was assessed by self-report using an illustrated questionnaire of pubertal stages according to the criteria of Tanner [24]. The participants were given photographs, figures and descriptions of breast and pubic hair development stages and asked to choose the one which most accurately reflected their appearance. 
Pubertal development according to the method of Tanner, which uses self-assessment of breast and pubic hair stages in girls, has been validated previously $[25,26]$ and was used in our previous studies with girls $[4,6,18,23]$. All girls in this study were in Tanner stage 1 . Bone age was assessed with an X-ray of the left hand and wrist, and determined according to the method of Greulish and Pyle [27].

\section{Body Composition and Bone Mineral Measurements}

Body composition (body fat \%, FM, and FFM), and BMD $\left(\mathrm{g} / \mathrm{cm}^{2}\right)$ from whole body (WB), and BMD from lumbar spine (LS) and femoral neck (FN) were measured by dual energy X-ray absorptiometry (DXA) using the DPX-IQ densitometer (Lunar Corp., Madison, Wisc., USA) equipped with proprietary software, version 3.6. Participants were scanned in light clothing while lying flat on their backs with arms on their sides. The fast scan mode and standard subject positioning were used for total body measurements, which were analyzed with use of the extended analysis option. DXA measurements were evaluated by the same examiner. Coefficients of variation (CVs) for the DXA measurements were less than $2 \%$. DXA is widely available, precise and safe and has become the preferred clinical instrument to assess bone development in children [28].

\section{Blood Sampling and Analysis}

Venous blood samples were drawn in both years between 07: 30 and 08:30 h after an overnight fasting from an antecubital vein with the participant sitting in the upright position. The plasma was separated and frozen at $-20^{\circ} \mathrm{C}$ for later analysis. Adiponectin was determined in duplicate via commercially available radioimmunoassay (RIA) kit (cat. No. HADP-61HK; Linco Research, Inc. St. Charles, Mo., USA), the intra- and interassay CVs were $<7 \%$, and the least detection limit was $1 \mu \mathrm{g} / \mathrm{ml}$. Leptin concentration was determined in duplicate by RIA (Mediagnost $\mathrm{GmbH}$, Reutlingen, Germany) and this assay has the intra- and interassay $\mathrm{CV}$ values less than $5 \%$, and the least detection limit was $0.01 \mathrm{ng} /$ $\mathrm{ml}$. Ghrelin was also determined in duplicate using a commercially available RIA kit (Linco Research, Inc.). The sensitivity of this kit was $93 \mathrm{pg} / \mathrm{ml}$, and the intra- and interassay CVs were $<10$ and $14.7 \%$, respectively.

\section{Statistical Analysis}

Statistical analyses were performed with SPSS 16.0 for Windows (SPSS, Chicago, Ill., USA), and the means and standard deviations $( \pm S D)$ were determined. Paired t tests were performed to determine the changes in measured variables over the 12-month study period. The comparisons between chronological age and bone age were also performed using the paired $t$ test. Independent $t$ tests were used to compare differences between groups. The least significant change (LSC) for measured BMD variables was also calculated [29] resulting in an LSC of 3.1\% at the measured sites. Pearson correlation coefficients were computed to explore the relationship between changes in BMD values during a 12-month study period with baseline body composition and blood biochemical variables. Stepwise multiple regression analysis was performed to determine the possible independent associations of an increase in measured BMD values over a 12-month study period with baseline bone age, BMI, FM, FFM, leptin, adiponectin and ghrelin values. The level of significance was set at $\mathrm{p}<0.05$.

Adipocytokines and Bone Mineralization in Prepubertal Girls

\section{Results}

Mean age, bone age, height $(+4.8 \%)$, body mass (+8.5\%), body fat $\%(+5.4 \%), \mathrm{FM}(+5.8 \%)$, FFM $(+9.8 \%)$, WB BMD $(+3.4 \%)$, LS BMD (+6.7\%), FN BMD (+6.4\%) and adiponectin $(+14.1 \%)$ were significantly increased $(\mathrm{p}<0.05)$, while ghrelin $(-17.2 \%)$ was significantly decreased $(\mathrm{p}<$ 0.05 ) after a 12 -month study period in RG (table 1). No changes ( $p>0.05)$ in BMI and leptin were observed over the 12-month study period in RG. In UC, significant increases $(\mathrm{p}<0.05)$ in mean age, bone age, height $(+4.9 \%)$, body mass $(+12.9 \%)$, BMI $(+2.4 \%)$, FM $(+19.6 \%)$, FFM $(+11.1 \%), \mathrm{WB}$ BMD $(+3.6 \%), \mathrm{LS}$ BMD $(+7.2 \%), \mathrm{FN}$ BMD $(+5.6 \%)$, leptin $(+22.0 \%)$ and adiponectin $(+17.8 \%)$ were observed. In addition, significant decreases $(p<0.05)$ in ghrelin $(-30.3 \%)$ occurred over the 12-month study period in controls (table 1). Therefore, the increases in bone age over the 12-month study period were significantly lower $(p=0.013)$ in $R G$ when compared with UC, while the increases in LS BMD over the 12-month study period were significantly higher $(\mathrm{p}=0.044)$ in RG when compared with UC. Changes in all other measured variables over the 12-month study period were not significantly different $(p>0.05)$ between the groups studied. In addition, the increases in measured BMD variables in both groups were higher with respect to the calculated LSC of $3.1 \%$.

Changes in WB and LS BMD values were significantly related to baseline age, while changes in FN BMD were significantly related to baseline height and body mass values in RG (table 2). All other relationships between changes in BMD values with measured body composition and blood biochemical variables were not significant $(\mathrm{r}<0.242 ; \mathrm{p}>0.05)$ in RG. In addition, stepwise multiple regression analysis revealed that measured baseline-independent variables did not predict $(p>0.05)$ increases in BMD values over the 12-month study period in RG.

Increases in WB BMD were significantly correlated with baseline height, body mass, BMI, body fat \%, FM, FFM, leptin and ghrelin values in UC (table 2). No significant correlations were observed between increases in LS BMD and measured baseline body composition and blood biochemical variables, while increases in FN BMD were related to baseline height, body mass, FFM and adiponectin values in UC. In UC, stepwise multiple regression analysis demonstrated that baseline FM and FFM values together were the most significant predictors of $\Delta \mathrm{WB} B M D$ and $\triangle \mathrm{FN} B M D$ values, explaining 25.2 and $15.7 \%$ of the variability in $\triangle \mathrm{WB} B M D$ and $\Delta \mathrm{FN} B M D$ values, respectively. When the influence of baseline bone 
Table 1. Mean $( \pm S D)$ of subject characteristics before and after a 12-month study period

\begin{tabular}{|c|c|c|c|c|c|c|}
\hline & \multicolumn{3}{|c|}{ Gymnasts $(\mathrm{n}=33)$} & \multicolumn{3}{|c|}{ Controls $(n=35)$} \\
\hline & before & after & $\mathrm{p}$ value & before & after & $\mathrm{p}$ value \\
\hline Age, years & $8.0 \pm 0.6$ & $9.0 \pm 0.6$ & 0.001 & $8.2 \pm 0.6$ & $9.3 \pm 0.5$ & 0.001 \\
\hline Bone age, years & $7.9 \pm 1.4$ & $8.6 \pm 1.5^{*}$ & 0.001 & $8.0 \pm 1.1$ & $9.3 \pm 0.8$ & 0.001 \\
\hline Height, cm & $130.2 \pm 5.1$ & $136.4 \pm 6.5$ & 0.001 & $129.9 \pm 5.8$ & $135.9 \pm 6.4$ & 0.001 \\
\hline Body mass, kg & $27.2 \pm 3.3$ & $29.5 \pm 3.3$ & 0.001 & $28.1 \pm 5.3$ & $31.5 \pm 6.3$ & 0.001 \\
\hline BMI & $15.7 \pm 1.1$ & $15.9 \pm 1.3$ & 0.490 & $16.6 \pm 2.2$ & $16.9 \pm 2.4$ & 0.030 \\
\hline Fat mass, kg & $4.7 \pm 1.6$ & $5.5 \pm 1.7$ & 0.001 & $6.7 \pm 2.9$ & $8.0 \pm 3.7$ & 0.001 \\
\hline Fat-free mass, $\mathrm{kg}$ & $19.9 \pm 4.0$ & $22.4 \pm 2.2$ & 0.001 & $19.9 \pm 2.5$ & $22.0 \pm 3.1$ & 0.001 \\
\hline Body fat, \% & $18.4 \pm 4.5$ & $19.4 \pm 4.5$ & 0.001 & $24.1 \pm 7.1$ & $25.5 \pm 7.9$ & 0.001 \\
\hline $\mathrm{WB} \mathrm{BMD}, \mathrm{g} / \mathrm{cm}^{2}$ & $0.87 \pm 0.04$ & $0.90 \pm 0.04$ & 0.001 & $0.85 \pm 0.05$ & $0.87 \pm 0.06$ & 0.001 \\
\hline $\mathrm{LS} \mathrm{BMD}, \mathrm{g} / \mathrm{cm}^{2}$ & $0.74 \pm 0.07$ & $0.79 \pm 0.08$ & 0.001 & $0.70 \pm 0.09$ & $0.74 \pm 0.09$ & 0.001 \\
\hline $\mathrm{FN} \mathrm{BMD}, \mathrm{g} / \mathrm{cm}^{2}$ & $0.78 \pm 0.07$ & $0.83 \pm 0.07$ & 0.029 & $0.71 \pm 0.08$ & $0.75 \pm 0.08$ & 0.083 \\
\hline Leptin, ng/ml & $2.0 \pm 1.3$ & $2.3 \pm 1.5$ & 0.125 & $4.2 \pm 2.6$ & $5.0 \pm 3.3$ & 0.038 \\
\hline Adiponectin, $\mu \mathrm{g} / \mathrm{ml}$ & $9.8 \pm 4.0$ & $11.3 \pm 4.2$ & 0.002 & $10.4 \pm 4.3$ & $11.9 \pm 3.5$ & 0.017 \\
\hline Ghrelin, pg/ml & $1,404.0 \pm 494.6$ & $1,189.3 \pm 387.3$ & 0.001 & $1,172.0 \pm 341.0$ & $829.0 \pm 385.8$ & 0.001 \\
\hline
\end{tabular}

$\mathrm{WB}=$ Whole body; LS = lumbar spine; FN = femoral neck; BMD = bone mineral density; $\mathrm{BMI}=$ body mass index.

p shows the significance before and after a study period in both groups. ${ }^{*}$ Significantly different from the age: $\mathrm{p}<0.05$.

Table 2. Pearson correlation coefficients of change ( $\Delta$ scores) in BMD values during the 12 -month study period with baseline body composition and blood biochemical variables

\begin{tabular}{|c|c|c|c|c|c|c|}
\hline & \multicolumn{3}{|c|}{ Gymnasts $(\mathrm{n}=33)$} & \multicolumn{3}{|c|}{ Controls $(\mathrm{n}=35)$} \\
\hline & $\begin{array}{l}\Delta W B \text { BMD } \\
\mathrm{g} / \mathrm{cm}^{2}\end{array}$ & $\begin{array}{l}\Delta \mathrm{LS} \text { BMD } \\
\mathrm{g} / \mathrm{cm}^{2}\end{array}$ & $\begin{array}{l}\Delta \mathrm{FN} \mathrm{BMD} \\
\mathrm{g} / \mathrm{cm}^{2}\end{array}$ & $\begin{array}{l}\Delta \mathrm{WB} \text { BMD } \\
\mathrm{g} / \mathrm{cm}^{2}\end{array}$ & $\begin{array}{l}\Delta \mathrm{LS} \text { BMD } \\
\mathrm{g} / \mathrm{cm}^{2}\end{array}$ & $\begin{array}{l}\Delta \text { FN BMD } \\
\mathrm{g} / \mathrm{cm}^{2}\end{array}$ \\
\hline Age, years & $0.369^{*}$ & $0.402^{*}$ & 0.242 & -0.006 & 0.131 & 0.315 \\
\hline Bone age, years & 0.126 & -0.069 & 0.234 & 0.103 & -0.060 & 0.234 \\
\hline Body height, $\mathrm{cm}$ & 0.138 & 0.118 & $0.434^{*}$ & $0.367^{*}$ & 0.036 & $0.340^{*}$ \\
\hline Body mass, kg & 0.080 & 0.000 & $0.361^{*}$ & $0.490^{*}$ & -0.075 & $0.339^{*}$ \\
\hline BMI & -0.005 & -0.126 & 0.086 & $0.475^{*}$ & -0.153 & 0.207 \\
\hline Fat mass, kg & 0.126 & 0.217 & 0.220 & $0.502^{*}$ & -0.097 & 0.235 \\
\hline Fat free mass, kg & 0.058 & -0.156 & 0.238 & $0.467^{*}$ & -0.071 & $0.396^{*}$ \\
\hline Body fat, $\%$ & 0.153 & 0.275 & 0.130 & $0.483^{*}$ & -0.108 & 0.111 \\
\hline Leptin, ng/ml & -0.078 & 0.211 & 0.172 & $0.352^{*}$ & -0.150 & 0.219 \\
\hline Adiponectin, $\mu \mathrm{g} / \mathrm{ml}$ & 0.319 & 0.294 & -0.008 & 0.029 & -0.0084 & $-0.392^{*}$ \\
\hline Ghrelin, pg/ml & -0.040 & -0.033 & -0.208 & $-0.394^{*}$ & 0.114 & 0.284 \\
\hline
\end{tabular}

$\Delta \mathrm{WB}=$ Whole body; $\Delta \mathrm{LS}=$ lumbar spine; $\Delta \mathrm{FN}=$ femoral neck; $\mathrm{BMD}=$ bone mineral density; $\mathrm{BMI}=$ body mass index.

* Statistically significant: $\mathrm{p}<0.05$.

age, BMI, FM and FFM was excluded, baseline ghrelin and adiponectin concentrations were the most important hormonal predictors of $\triangle \mathrm{WB} B M D$ and $\triangle F N$ BMD values in the UC group, explaining $15.5 \%$ in $\Delta \mathrm{WB} B M D$ and
$15.3 \%$ in $\triangle \mathrm{FN}$ BMD values, respectively. In addition, stepwise regression analysis demonstrated no association between $\triangle \mathrm{LS}$ BMD and measured baseline-independent variables in UC. 


\section{Discussion}

The relationships between increased BMD values with baseline leptin, adiponectin and ghrelin were studied in two different groups of prepubertal girls. The 12-month prospective study demonstrated significant changes in measured adipocytokine, ghrelin and body composition variables in UC, while no significant increases in leptin concentrations were found in RG. Therefore, the increases in measured BMD variables were higher with respect to the calculated LSC, indicating normal growth of BMD values in both groups of prepubertal girls over the 12 -month study period. While increases in adiponectin and body composition variables, and decreases in ghrelin were not significantly different between the groups studied, the increases in bone age over the 12-month study period were lower $(\mathrm{p}<0.05)$ in RG compared with UC, and the increases in LS BMD were higher $(\mathrm{p}<0.05)$ in RG compared with UC. It appeared that initial hormone concentrations together with specific body composition variables were associated with an increase in BMD in prepubertal UC but not in RG groups. These results suggest that due to mechanical loading, prepubertal RG may have a beneficial effect on bone mineralization and may have counterbalanced the negative factors on bone development such as low FM and leptin concentrations.

One of the main findings of the present investigation was that regular high-impact weight-bearing athletic activity promoted significant annual gains in BMD in relatively young prepubertal RG (table 1). The annual gain in $\mathrm{BMD}$ values in $\mathrm{RG}$ was close to the results of Courteix et al. [30]. Our previous cross-sectional study with 8-yearold RG found that at least 2 years of athletic training with high energy expenditure did not cause any delay in bone age maturation [4], which is a good marker of biological maturation [31, 32]. Interestingly, the results of the present study demonstrated that bone age was lower $(\mathrm{p}<0.05)$ than chronological age after a 12 -month study period in RG. A recent cross-sectional study by Maimoun et al. [7] also suggested that prepubertal RG had a significant delay in bone age, while Courteix et al. [30] found only a trend towards a lower bone age after a 12-month study period in highly trained prepubertal RG. Georgopoulos et al. [32] indicated that prepubertal stage is prolonged and pubertal development is shifted to a later age following the bone maturation rather than the chronological age in elite RG. These results together suggest that since prepubertal RG present significant annual gains in BMD and higher BMD values in comparison with same chronological age UC, they may also maintain higher bone

Adipocytokines and Bone Mineralization in Prepubertal Girls mineral values although bone age and biological maturation have been delayed.

Another main finding was that leptin was significantly increased in UC but not in RG over the 12-month study period (table 1). The mean leptin values in UC were similar to previous results in normal weight girls at a similar age [2]. It has been reported that circulating leptin starts to rise in the prepubertal period from 5 years and continues to progressively rise throughout puberty in healthy physically inactive girls [20, 33, 34]. Maimoun et al. [7] reported that leptin concentrations rise in parallel with the increase in FM in highly trained RG even with a reduced amount of adipose tissue progressing from prepuberty to puberty. These results together suggest that the specific physical activity pattern seen in our RG during earlier prepubertal years may have counterbalanced the age-dependent increase in circulating leptin concentrations and the increase in leptin levels could be seen at the onset of puberty in a specific group of young RG.

Baseline leptin concentrations did not predict increases in measured BMD values over the 12-month study period in RG. However, leptin was significantly correlated with $\triangle \mathrm{WB} B M D$ in UC. While other investigations have reported independent relationships between leptin and measured BMD variables in untrained prepubertal children $[2,4,9]$, recent studies did not find leptin as an independent predictor of BMD in a group of elite female RG at different pubertal stages $[4-7,15]$. Although leptin has been reported to be involved in the accumulation, maintenance and loss of BMD throughout life [35], the impact of leptin on growing human bone remains controversial $[4,7]$. Accordingly, the results of present study suggest that leptin is not longitudinally involved in the development of BMD in a specific group of RG before puberty.

Similar to previous studies, adiponectin increased [21] and ghrelin decreased [22] over the 12-month study period in both groups studied (table 1). Baseline adiponectin and ghrelin levels did not predict significant increases in BMD values in prepubertal RG, while baseline adiponectin was inversely correlated with $\triangle F N ~ B M D$ in UC. However, the independent variables that were associated with increases in BMD values were baseline FM and FFM values together in UC and only after excluding the influence of body composition parameters, ghrelin and adiponectin concentrations predicted increases in WB BMD and FN BMD values in UC, respectively. These results demonstrate that baseline adiponectin and ghrelin may not have a direct role in the development of BMD variables in prepubertal girls. In accordance with our results, previous studies have also found no relationship between 
adiponectin $[4,16]$ and ghrelin $[4,18]$ with BMD variables in physically active prepubertal children. Although some studies have reported significant correlations of BMD variables with adiponectin $[11,12]$ and ghrelin $[17$, $36]$, the results of current study suggest that during prepubertal development, adiponectin and ghrelin are not independent predictors of increases in BMD levels in contrast to FM and FFM values in prepubertal girls with different physical activity patterns. Taken together, further longitudinal studies from prepuberty to pubertal maturation are necessary to clarify the possible roles of adiponectin and ghrelin in the bone development in girls with different physical activity parameters.
In conclusion, body composition variables together with measured adipocytokine and ghrelin levels did not predict a normal growth in BMD values in RG. However, initial leptin together with specific body composition variables were associated with an increase in WB BMD value as a result of the 12-month study period in UC.

\section{Acknowledgement}

This study was supported by Estonian Science Foundation Grant GKKSP 8068.

\section{References}

1 MacKelvie KJ, Khan KM, McKay HA: Is there a critical period for bone response to weight-bearing exercise in children and adolescents? A systematic review. Br J Sports Med 2002;36:250-257.

2 Rhie YL, Lee KH, Chung SC, Kim HS, Kim $\mathrm{DH}$ : Effects of body composition, leptin, and adiponectin on bone mineral density in prepubertal girls. J Korean Med Sci 2010;25: 1187-1190.

3 Rizzoli R, Bianchi ML, Garabedian M, McKay HA, Moreno LA: Maximizing bone mineral mass gain during growth for the prevention of fractures in the adolescents and elderly. Bone 2010;46:294-305.

-4 Parm AL, Jürimäe J, Saar M, Pärna K, Tillmann V, Maasalu K, Neissaar I, Jürimäe T: Plasma adipocytokine and ghrelin levels in relation to bone mineral density in prepubertal rhythmic gymnasts. J Bone Miner Metab 2011;29:717-724.

$\checkmark 5$ Munoz MT, de la Piedra C, Barrios V, Garrido $G$, Argente J: Changes in bone density and bone markers in rhythmic gymnasts and ballet dancers: implications for puberty and leptin levels. Eur J Endocrinol 2004;151:491 496.

6 Gruodyté R, Jürimäe J, Cicchella A Stefanelli C, Passariello C, Jürimäe T: Adipocytokines and bone mineral density in adolescent female athletes. Acta Paediatr 2010;99:18791884.

7 Maimoun L, Coste O, Jaussen A, MarianoGoulart D, Sultan C, Paris F: Bone mass acquisition in female rhythmic gymnasts during puberty: no direct role for leptin. Clin Endocrinol 2010;72:604-611.

8 Reid IR: Relationships among body mass, its compartments, and bone. Bone 2002;31: 547-555.

-9 Garnett SP, Högler W, Blades B, Baur LA, Peat J, Lee J, Cowell CT: Relation between hormones and body composition, including bone, in prepubertal children. Am J Clin Nutr 2004;80:966-972.

10 Pacifico L, Anania C, Poggiogalle E, Osborn JF, Prossomariti G, Martino F, Chiesa C: Relationships of acylated and des-acyl ghrelin levels to bone mineralization in obese children and adolescents. Bone 2009;45:274279.

11 Huang KC, Cheng WC, Yen RF, Tsai KS, Tai TY, Yang WS: Lack of independent relationship between plasma adiponectin, leptin levels and bone density in nondiabetic female adolescents. Clin Endocrinol 2004;61:204208.

-12 Misra M, Miller KK, Cord J, Prabhakaran R, Herzog DB, Goldstein M, Katzman DK, Klibanski A: Relationships between serum adipokines, insulin levels, and bone density in girls with anorexia nervosa. J Clin Endocrinol Metab 2007;92:2046-2052.

13 Jürimäe J, Mäestu J, Jürimäe T, Mangus B, von Duvillard SP: Peripherial signals of energy homeostasis as possible markers of training stress in athletes: a review. Metab 2011;60:335-350.

14 Courteix D, Rieth N, Thomas T: Preserved bone health in adolescent elite rhythmic gymnasts despite hypoleptinemia. Horm Res 2007;68:20-27.

15 Maimoun L, Coste O, Galtier F, Mura T, Mariano-Goulart D: Bone mineral density acquisition in peripubertal female rhythmic gymnasts is directly associated with plasma IGF1/IGF-binding protein 3 ratio. Eur J Endocrinol 2010;163:157-164.

16 Russell M, Stark J, Nayak S, Miller KK, Herzog DB, Klibanski A, Misra M: Peptide YY in adolescent athletes with amenorrhea, eumenorrheic athletes and non-athletic controls. Bone 2009;45:104-109.

17 Misra M, Miller KK, Stewart V, Hunter E, Kuo K, Herzog DB, Klibanski A: Ghrelin and bone metabolism in adolescent girls with an- orexia nervosa and healthy adolescents. J Clin Endocrinol Metab 2005;90:5082-5087.

18 Jürimäe J, Lätt E, Haljaste K, Purge P, Cicchella A, Jürimäe T: A longitudinal assessment of ghrelin and bone mineral density with advancing pubertal maturation in adolescent female athletes. J Sports Med Phys Fitness 2010;50:343-349.

19 Roemmich JN, Clark PA, Berr SS, Mai V, Mantzoros CS, Flier JS, Weltman A, Rogol $\mathrm{AD}$ : Gender differences in leptin levels during puberty are related to the subcutaneous fat depot and sex steroids. Am J Physiol 1998; 273:E543-E551.

20 Mann DR, Johnson AO, Gimpel T, Castracane VD: Changes in circulating leptin, leptin receptor, and gonadal hormones from infancy until advanced age in humans. J Clin Endocrinol Metab 2003;88:3339-3345.

-21 Cambuli VM, Musiu MC, Incani M, Paderi M, Serpe R, Marras V, Cossu E, Cavallo MG, Mariotti S, Loche S, Baroni MG: Assessment of adiponectin and leptin as biomarkers of positive metabolic outcomes after lifestyle intervention in overweight and obese children. J Clin Endocrinol Metab 2008;93: 3051-3057.

22 Whatmore AJ, Hall CM, Jones J, Westwood M, Clayton PE: Ghrelin concentrations in healthy children and adolescents. Clin Endocrinol 2003;59:649-654.

23 Jürimäe J, Cicchella A, Jürimäe T, Lätt E, Haljaste K, Purge P, Hamra J, von Duvillard SP: Regular physical activity influences plasma ghrelin concentration in adolescent girls. Med Sci Sports Exerc 2007;39:1736-1741.

24 Tanner J: Growth at Adolescence, ed 2. Oxford, Blackwell Scientific, 1962.

25 Matsudo SMM, Matsudo VKR: Self-assessment and physician assessment of sexual maturation in Brazilian boys and girls: concordance and reproducibility. Am J Hum Biol 1994;6:451-455. 
26 Leone M, Comtois AS: Validity and reliability of self-assessment of sexual maturity in elite adolescent athletes. J Sports Med Phys Fitness 2007;47:361-365.

27 Greulish WW, Pyle SI: Radiographics Atlas of Skeletal Development of Hand and Wrist, ed 2. Stanford, Stanford University Press, 1959.

-28 Specker B, Schoenau E: Quantitative bone analysis in children: current methods and recommendations. J Pediatr 2005:726-731.

29 Leonard CM, Roza M, Barr RD, Webber CE: Reproducibility of DXA measurements of bone mineral density and body composition in children. Pediatr Radiol 2009;39:148-154.

-30 Courteix D, Lespessailles E, Jaffre C, Obert P, Benhamou CL: Bone mineral acquisition and somatic development in highly trained girl gymnasts. Acta Paediatr 1999;88:803808.
31 Beunen GP, Malina RM, Lefevre J, Claessens AL, Renson R, Kanden Eynde B, Vanreusel B, Simons J: Skeletal maturation, somatic growth and physical fitness in girls 6-16 years of age. Int J Sports Med 1997;18:413419.

32 Georgopoulos NA, Roupas ND, Theodoropoulou A, Tsekouras A, Vagenakis AG, Markou KB: The influence of intensive physical training on growth and pubertal development in athletes. Ann NY Acad Sci 2010; 1205:39-44.

33 Blum WF, Englaro P, Hanitsch S, Juul A, Hertel NT, Müller J, Skakkebaek NE, Heiman ML, Birkett M, Attanasio AM, Kiess W, Rascher W: Plasma leptin levels in healthy children and adolescents: dependence on body mass index, body fat mass, gender, pubertal stage, and testosterone. J Clin Endocrinol Metab 1997;82:2904-2910.
34 Garcia-Mayor RV, Andrade A, Rios M, Lage M, Dieguez C, Casanueva FF: Serum leptin levels in normal children: relationships to age, gender, body mass index, pituitary-gonadal hormones, and pubertal stage. J Clin Endocrinol Metab 1997;82:2849-2855.

35 Hamrick MW, Ferrari SL: Leptin and the sympathetic connection of fat to bone. Osteoporos Int 2008;19:905-912.

36 Makovey J, Naganathan V, Seibel M, Sambrook P: Gender differences in plasma ghrelin and its relations to body composition and bone - an opposite-sex twin study. Clin Endocrinol 2007;66:530-537. 